\title{
Indole Alkaloids Inhibiting Neural Stem Cell from Uncaria rhynchophylla
}

\author{
Xin Wei $\cdot$ Li-Ping Jiang $\cdot$ Ying Guo • \\ Afsar Khan • Ya-Ping Liu • Hao-Fei Yu • \\ Bei Wang $\cdot$ Cai-Feng Ding $\cdot$ Pei-Feng Zhu • \\ Ying-Ying Chen $\cdot$ Yun-Li Zhao $\cdot$ Yong-Bing Chen $\cdot$ \\ Yi-Fen Wang $\cdot$ Xiao-Dong Luo
}

Received: 4 August 2017/ Accepted: 12 September 2017/Published online: 26 September 2017

(C) The Author(s) 2017. This article is an open access publication

\begin{abstract}
Uncaria rhynchophylla is commonly recognized as a traditional treatment for dizziness, cerebrovascular diseases, and nervous disorders in China. Previously, the neuro-protective activities of the alkaloids from $U$. rhynchophylla were intensively reported. In current work, three new indole alkaloids (1-3), identified as geissoschizic acid (1), geissoschizic acid $N_{4}$-oxide (2), and $3 \beta$-sitsirikine $N_{4}$-oxide (3), as well as 26 known analogues were isolated from $U$. rhynchophylla. However, in the neural stem cells (NSCs) proliferation assay for all isolated compounds, geissoschizic acid (1), geissoschizic acid $N_{4}$-oxide (2), isocorynoxeine (6), isorhynchophylline (7), (4S)-akuammigine $N$-oxide (8), and (4S)rhynchophylline $N$-oxide (10) showed unexpected inhibitory activities at $10 \mu \mathrm{M}$. Unlike previous neuro-protective reports, as a warning or caution, our finding showcased a clue for possible NSCs toxicity and the neural lesions risk of $U$. rhynchophylla, while the structure-activity relationships of the isolated compounds were discussed also.
\end{abstract}

Keywords Uncaria rhynchophylla $\cdot$ Indole alkaloids $\cdot$ NSCs proliferation

\section{Introduction}

The dried stem and hook of Uncaria rhynchophylla, named as Gou-teng or Cat's claw, was used for treatment of dizziness, cerebrovascular diseases, and nervous disorders

Electronic supplementary material The online version of this article (doi:10.1007/s13659-017-0141-y) contains supplementary material, which is available to authorized users.

X. Wei · Y. Guo · Y.-P.Liu - H.-F. Yu - B. Wang - C.-F. Ding · P.-F. Zhu · Y.-Y. Chen · Y.-L. Zhao · Y.-F. Wang (ه) ·

X.-D. Luo $(\square)$

State Key Laboratory of Phytochemistry and Plant Resources in West China, Kunming Institute of Botany, Chinese Academy of Sciences, Kunming 650201, People's Republic of China e-mail: wangyifen@mail.kib.ac.cn

X.-D. Luo

e-mail:xdluo@mail.kib.ac.cn

X. Wei · L.-P. Jiang - Y. Guo · H.-F. Yu - B. Wang ·

C.-F. Ding · P.-F. Zhu

University of Chinese Academy of Sciences, Beijing 100049,

People's Republic of China
$[1,2]$. Up to now, detailed phytochemical research resulted in more than 90 indole alkaloids from U. rhynchophylla [2]. Its alkaloids, commonly recognized as bioactive ingredients, are responsible for the pharmacological activities closely related to neuro-protective effects [2]. Previously, the neuro-protective activities of the total alkaloids and the main monomeric indoles from U. rhynchophylla were reported [3-7]. Over the past few years,

L.-P. Jiang · Y.-B. Chen

Key Laboratory of Animal Models and Human Disease Mechanisms, Kunming Institute of Zoology, Chinese Academy of Sciences, Kunming 650223, People's Republic of China

A. Khan

Department of Chemistry, COMSATS Institute of Information Technology, Abbottabad 22060, Pakistan

X.-D. Luo

Yunnan Key Laboratory of Natural Medicinal Chemistry, Kunming 650201, People's Republic of China 
continuing research on neuro-protective activities of $U$. rhynchophylla have culminated in considerable discoveries [8-11].

In adult nervous system, neural stem cells (NSCs) can self-renew and differentiate into almost all types of neural cells $[12,13]$. Thus, countless new neurons are sustained throughout adulthood [12]. Recent medical research suggested many neurodegenerative diseases, such as Parkinson's disease or Alzheimer's disease (AD), may benefit from NSCs transplantation as well as its differentiation and proliferation capacity [14]. Enlightened by the importance of NSCs, small molecules and natural products promoting the NSCs differentiation and proliferation been intensively investigated [15, 16]. However, a very little work been focused on the substances or compounds with inhibitory effects, which may contribute to the possible risk of neural lesions [17].

As our ongoing search for novel and bioactive alkaloids as well as further NSCs related evaluation [16, 18], the detailed chemical investigation on hook-bearing branches of $U$. rhynchophylla was carried out. As a result, three new indole alkaloids, geissoschizic acid (1), geissoschizic acid $N_{4}$-oxide (2), $3 \beta$-sitsirikine $N_{4}$-oxide (3), along with 26 known analogues (Fig. 1), geissoschizine methyl ether (4) [19], sitsirikine (5) [20], isocorynoxeine (6) [21], isorhynchophylline (7) [21], (4S)-akuammigine $N$-oxide (8) [22], cadambine (9) [23], (4S)-rhynchophylline $N$-oxide (10) [24], isorhynchophylline $N_{4}$-oxide (11) [25], (4S)-isocorynoxeine $N$-oxide (12) [24], corynoxeine (13) [21], rhynchophylline (14) [21], (4S)-corynoxeine $N$-oxide (15) [24], geissoschizine methyl ether $N_{4}$-oxide (16) [26], 3-epigeissoschizine methyl ether (17) [21], akuammigine (18) [27], (4R)-akuammigine $N$-oxide (19) [22], corynantheine (20) [28], dihydrocorynantheine (21) [28], hirsuteine (22) [23], hirsutine $N$-oxide (23) [29], hirsutine (24) [23], dihydrocorynantheine $N$-oxide (25) [30], hirsuteine $N$-oxide (26) [29], 3 $\alpha$-dihydrocadambine (27) [31], nitrocadambine B (28) [32], and augustine (29) [33], were isolated. NSCs proliferation assay for all the compounds (1-29) with DMSO and puromycin as the control groups exhibited the unexpected inhibitory activities of compounds 1-2, 6-8, and 10 at $10 \mu \mathrm{M}$ (Table 1). Besides reported neuro-protective activities, the tested results shed a light on the possible NSCs toxicity and and the neural lesions risk of $U$. rhynchophylla, as a warning or caution. Meanwhile, the structure-activity relationships of the compounds mentioned above were discussed herein by structural analysis.

\section{Results and Discussion}

Compound $\mathbf{1}$ was assigned a molecular formula $\mathrm{C}_{21} \mathrm{H}_{24} \mathrm{~N}_{2} \mathrm{O}_{3}$ from HRESIMS ion at $m / z$ 353.1852 [M+H] $]^{+}$ (calcd for $\mathrm{C}_{21} \mathrm{H}_{25} \mathrm{~N}_{2} \mathrm{O}_{3}, 353.1860$ ). The $\mathrm{UV}$ spectrum showed absorption maxima characteristic of an indolenine chromophore $(269,223,207 \mathrm{~nm})$ [34]. The IR spectrum showed absorption bands at $3421(\mathrm{~N}-\mathrm{H})$ and $1644 \mathrm{~cm}^{-1}$

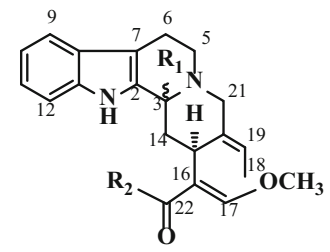

$\mathbf{1}^{*} \mathbf{R}_{1}=\alpha_{\mathbf{H}}, \mathbf{R}_{\mathbf{2}}=\mathbf{O H}$

$2 * \mathbf{R}_{1}=\alpha_{\mathbf{H}}, \mathbf{R}_{2}=\mathrm{OH}, \mathrm{N}_{4}$-oxide

$4 \mathbf{R}_{1}=\alpha_{\mathbf{H}}, \mathbf{R}_{2}=\mathrm{OCH}_{3}$

$16 R_{1}=\alpha_{H}, R_{2}=O C H_{3}, N_{4}$-oxide

$17 \mathbf{R}_{1}=\beta H, \mathbf{R}_{2}=\mathrm{OCH}_{3}$

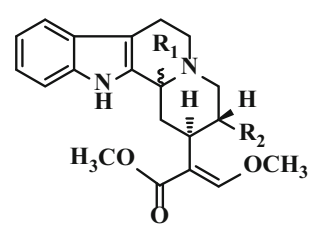

$20 \mathbf{R}_{1}=\alpha+\mathbf{R}_{2}=\mathbf{C H}=\mathrm{CH}_{2}$

$21 \mathbf{R}_{1}=\alpha_{\mathbf{H}}, \mathbf{R}_{2}=\mathrm{CH}_{2}-\mathrm{CH}_{3}$

$22 \mathbf{R}_{1}=\beta \mathbf{H}, \mathbf{R}_{2}=\mathbf{C H}=\mathrm{CH}_{2}$

$23 \mathbf{R}_{1}=\beta H, \mathbf{R}_{2}=\mathrm{CH}_{2}-\mathrm{CH}_{3}, N_{4}$-oxide

$24 \mathbf{R}_{1}=\beta H, \mathbf{R}_{2}=\mathrm{CH}_{2}-\mathrm{CH}_{3}$

$25 \mathbf{R}_{1}=\alpha_{\mathbf{H}}, \mathbf{R}_{2}=\mathrm{CH}_{2}-\mathrm{CH}_{3}, \mathrm{~N}_{4}$-oxide

$26 \mathbf{R}_{1}=\beta H, \mathbf{R}_{2}=\mathrm{CH}=\mathrm{CH}_{2}, N_{4}$-oxide
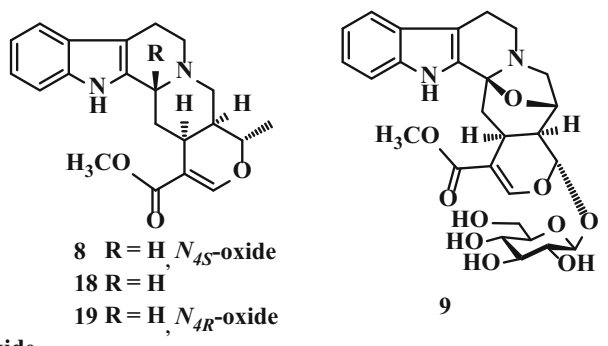

9

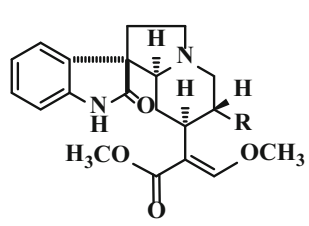

$10 \mathrm{R}=\mathrm{CH}_{2}-\mathrm{CH}_{3}, \mathrm{~N}_{4}$-oxide

$13 \mathrm{R}=\mathrm{CH}=\mathrm{CH}_{2}$,

$14 \mathrm{R}=\mathrm{CH}_{2}-\mathrm{CH}_{3}$

$11 \mathrm{R}=\mathrm{CH}_{2}-\mathrm{CH}_{3}, N_{4}$-oxide

$12 \mathrm{R}=\mathrm{CH}=\mathrm{CH}_{2}, N_{4}$-oxide

$15 \mathrm{R}=\mathrm{CH}=\mathrm{CH}_{2}, N_{4}$-oxide

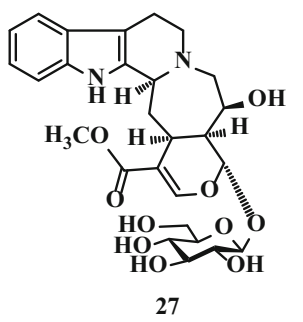

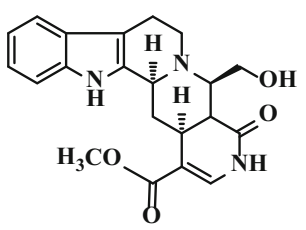

28<smiles>C=Cc1cncc2c(=O)n3c(cc12)-c1[nH]c2ccccc2c1CC3</smiles>

29

Fig. 1 Structures of compounds 1-29 
Table 1 NSCs Proliferation of Compounds 1-2, 6-8, and 10 at $10 \mu \mathrm{M}$

\begin{tabular}{llll}
\hline Compound & Proliferation $(\%)$ & Compound & Proliferation $(\%)$ \\
\hline $\mathbf{1}$ & 56.7 & $\mathbf{8}$ & 56.5 \\
$\mathbf{2}$ & 87.8 & $\mathbf{1 0}$ & 76.5 \\
$\mathbf{6}$ & 73.2 & Puromycin $^{\mathrm{a}}$ & 17.1 \\
$\mathbf{7}$ & 68.8 & DMSO $^{\mathrm{b}}$ & 100.0 \\
\hline
\end{tabular}

${ }^{\mathrm{a} P o s i t i v e ~ c o n t r o l ~}(10 \mu \mathrm{M})$

${ }^{\mathrm{b}}$ Negative control

$(\mathrm{C}=\mathrm{O})$. The ${ }^{1} \mathrm{H}$ NMR spectroscopic data (Table 2) revealed signals for non-substituted a ring of indole system [34], a methoxyl group, an olefinic proton, and a methyl group.
The ${ }^{13} \mathrm{C}$ NMR and DEPT spectra showed a total of 21 carbon resonances, including one methyl, one methoxyl, four methylenes, eight methines, and seven quaternary carbons. The ${ }^{1} \mathrm{H}$ and ${ }^{13} \mathrm{C}$ NMR spectroscopic data of $\mathbf{1}$ (Table 2) was similar to those of geissoschizine methyl ether (4) [19] except methoxyl group in 4, substituent by $\mathrm{OH}$ in $\mathbf{1}$, consistent with its molecular formula. The typical chemical shift of $-\mathrm{OCH}_{3}\left(\delta_{\mathrm{C}} 61.4\right)$ at $\mathrm{C}-17$, was present in ${ }^{13} \mathrm{C}$ NMR spectrum of $\mathbf{1}$, and further supported by correlation of $\delta_{\mathrm{H}} 3.74\left(\mathrm{~s},-\mathrm{OCH}_{3}\right)$ with $\delta_{\mathrm{C}} 158.5(\mathrm{C}-17)$ in its HMBC spectrum (Fig. 2), which suggested that $\mathbf{1}$ was hydrolysate of 4 . In the tetracyclic indole alkaloid (1), the absolute configuration of C-3 was determined as $S$ according to a positive cotton effect at $267 \mathrm{~nm}$, while negative

Table $2{ }^{1} \mathrm{H}$ and ${ }^{13} \mathrm{C}$ NMR Spectroscopic Data of 1-3 $(\delta$ in ppm, $J$ in $\mathrm{Hz})$

\begin{tabular}{|c|c|c|c|c|c|c|}
\hline \multirow[t]{2}{*}{ Position } & \multicolumn{2}{|l|}{1} & \multicolumn{2}{|l|}{2} & \multicolumn{2}{|l|}{3} \\
\hline & $\delta_{\mathrm{H}}^{\mathrm{a}}$ & $\delta_{\mathrm{C}}^{\mathrm{c}}$ & $\delta_{\mathrm{H}}^{\mathrm{a}}$ & $\delta_{\mathrm{C}}^{\mathrm{d}}$ & $\delta_{\mathrm{H}}^{\mathrm{b}}$ & $\delta_{\mathrm{C}}^{\mathrm{d}}$ \\
\hline 2 & & 131.9 & & 131.0 & & 130.3 \\
\hline 3 & $4.20(\mathrm{dd}, 3.7,11.7)$ & 57.7 & $4.29(\mathrm{~d}, 12.2)$ & 75.0 & 4.59 (br. s) & 71.6 \\
\hline \multirow[t]{2}{*}{5} & $3.34(\mathrm{dd}, 5.1,12.0)$ & 51.1 & 3.76 (overlap) & 63.2 & 3.66 (overlap) & 69.4 \\
\hline & $3.16(\mathrm{ddd}, 5.1,7.4,12.0)$ & & $3.56(\mathrm{~m})$ & & 3.66 (overlap) & \\
\hline \multirow[t]{2}{*}{6} & $2.99(\mathrm{~m})$ & 20.6 & 3.29 (overlap) & 18.9 & $3.09(\mathrm{~m})$ & 20.6 \\
\hline & $2.88(\mathrm{dt}, 5.1,5.1,10.9)$ & & 2.88 (br. d, 14.1) & & $3.02(\mathrm{~m})$ & \\
\hline 7 & & 107.5 & & 106.9 & & 106.8 \\
\hline 8 & & 127.5 & & 127.9 & & 127.6 \\
\hline 9 & $7.41(\mathrm{~d}, 7.8)$ & 119.0 & $7.46(\mathrm{~d}, 7.8)$ & 119.6 & $7.36(\mathrm{~d}, 7.8)$ & 119.1 \\
\hline 10 & $7.00(\mathrm{t}, 7.8)$ & 120.3 & $7.00(\mathrm{t}, 7.8)$ & 120.7 & $6.96(t, 7.8)$ & 120.7 \\
\hline 11 & $7.09(\mathrm{t}, 7.8)$ & 123.0 & $7.08(\mathrm{t}, 7.8)$ & 123.3 & $7.05(\mathrm{t}, 7.8)$ & 123.4 \\
\hline 12 & $7.30(\mathrm{~d}, 7.8)$ & 112.2 & $7.28(\mathrm{~d}, 7.8)$ & 112.5 & $7.28(\mathrm{~d}, 7.8)$ & 112.6 \\
\hline 13 & & 138.5 & & 138.9 & & 138.9 \\
\hline$H_{\alpha}-14$ & $2.42(\mathrm{ddd}, 3.7,7.9,14.0)$ & 32.6 & $2.23(\mathrm{~m})$ & 34.6 & $2.26(\mathrm{ddd}, 2.2,12.8,14.2)$ & 25.1 \\
\hline $\mathrm{H}_{\beta}-14$ & $2.30(\mathrm{ddd}, 8.9,11.7,14.0)$ & & $2.34(\mathrm{~m})$ & & $2.60(\mathrm{dt}, 5.0,14.2)$ & \\
\hline 15 & $4.09(\mathrm{~d}, 7.9)$ & 33.6 & $4.10(\mathrm{~d}, 6.9)$ & 36.2 & $1.47(\mathrm{tt}, 1.5,12.2,12.8)$ & 35.1 \\
\hline 16 & & 117.5 & & 117.7 & $2.78(\mathrm{ddd}, 2.8,6.1,8.5)$ & 49.1 \\
\hline \multirow[t]{2}{*}{17} & $7.20(\mathrm{~s})$ & 158.5 & $7.16(\mathrm{~s})$ & 158.1 & $3.92(\mathrm{dd}, 8.4,11.0)$ & 62.3 \\
\hline & & & & & $3.52(\mathrm{dd}, 6.3,11.0)$ & \\
\hline \multirow[t]{2}{*}{18} & $1.64(\mathrm{~d}, 6.6)$ & 13.5 & $1.68(\mathrm{~d}, 6.4)$ & 14.3 & $5.18(\mathrm{dd}, 1.8,17.1)$ & 120.4 \\
\hline & & & & & $5.08(\mathrm{dd}, 1.8,10.0)$ & \\
\hline 19 & $5.53(\mathrm{q}, 6.6)$ & 126.5 & $5.73(\mathrm{q}, 6.4)$ & 131.4 & $5.31(\mathrm{~m})$ & 137.4 \\
\hline 20 & & 133.0 & & 132.8 & $3.04(\mathrm{~m})$ & 40.7 \\
\hline $\mathbf{H}_{\alpha}-21$ & $3.62(\mathrm{~d}, 13.1)$ & 61.1 & $5.07(\mathrm{~d}, 11.7)$ & 78.7 & $3.32(\mathrm{t}, 11.9)$ & 63.0 \\
\hline $\mathbf{H}_{\beta}-21$ & $4.07(d, 13.1)$ & & 3.76 (overlap) & & $2.90(\mathrm{dd}, 3.5,11.9)$ & \\
\hline 22 & & 174.7 & & 175.5 & & 174.4 \\
\hline OMe_17 & $3.74(\mathrm{~s})$ & 61.4 & $3.72(\mathrm{~s})$ & 61.6 & & \\
\hline OMe_22 & & & & & $3.64(\mathrm{~s})$ & 52.0 \\
\hline
\end{tabular}

${ }^{a}$ Recorded at $400 \mathrm{MHz}$ in $\mathrm{CD}_{3} \mathrm{OD}$

${ }^{\mathrm{b}}$ Recorded at $600 \mathrm{MHz}$ in $\mathrm{CD}_{3} \mathrm{OD}$

${ }^{\mathrm{c}}$ Recorded at $100 \mathrm{MHz}$ in $\mathrm{CD}_{3} \mathrm{OD}$

${ }^{\mathrm{d}}$ Recorded at $150 \mathrm{MHz}$ in $\mathrm{CD}_{3} \mathrm{OD}$ 

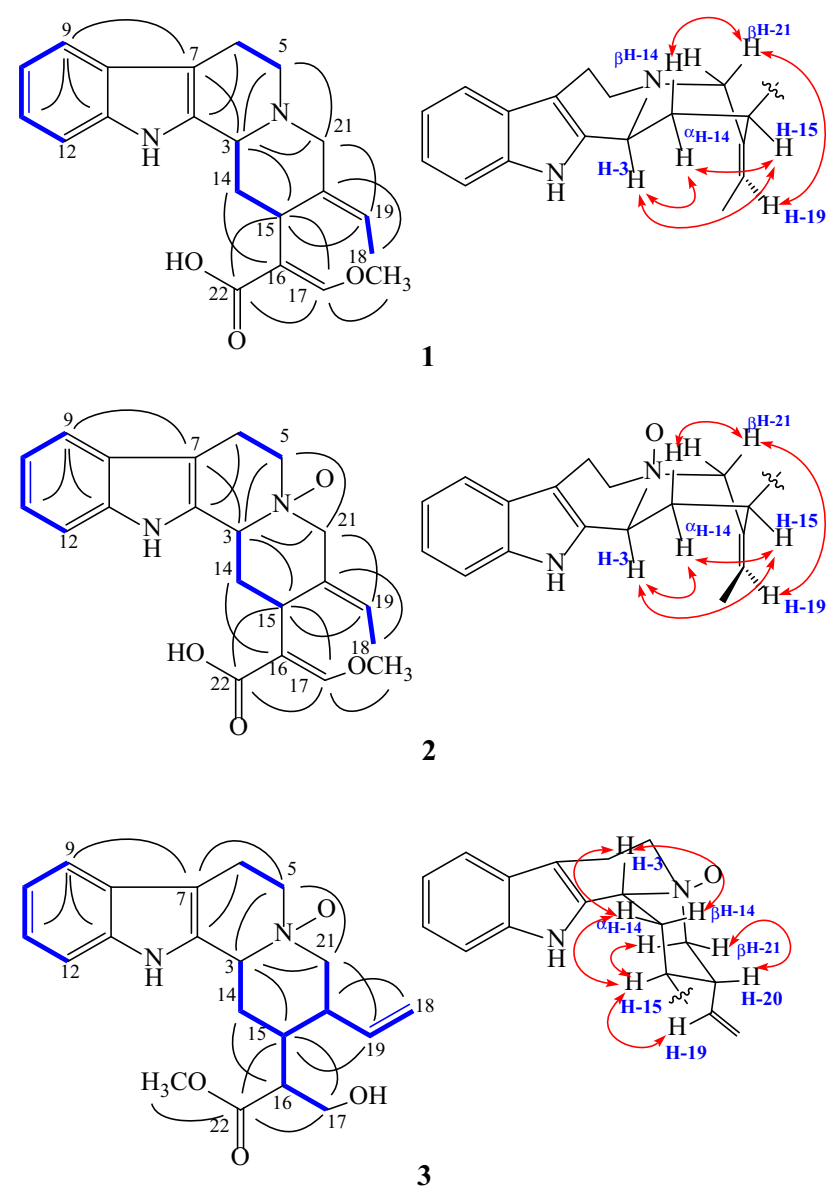

Fig. 2 Selective $\operatorname{HMBC}(\rightarrow),{ }^{1} \mathrm{H}-{ }^{1} \mathrm{H}$ COSY $(-)$, and $\operatorname{ROESY}(\leftrightarrow)$ correlations of compounds $\mathbf{1}-\mathbf{3}$

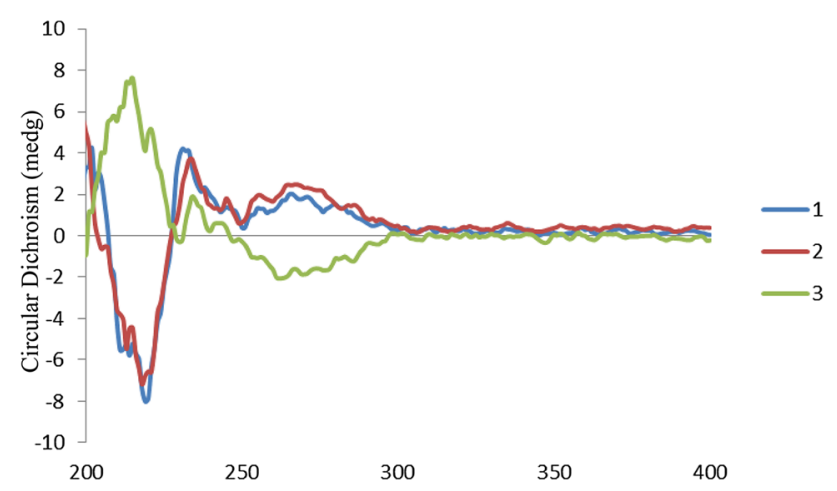

Fig. 3 ECD spectra of compounds 1-3

Cotton effect for $R$ (Fig. 3) [35]. Moreover, the NOE correlation of $\delta_{\mathrm{H}} 4.20(\mathrm{H}-3)$ with $\delta_{\mathrm{H}} 4.09(\mathrm{H}-15)$ in its ROESY spectrum, established C-15S (Fig. 2). The double bond of C-19/20 was $E$ by the ROESY correlations of $\delta_{\mathrm{H}}$ $4.07(\mathrm{H}-21) / 5.53$ (H-19) (Fig. 2). Meanwhile, the trans double bond of C-16/17 was indicated by the upfield chemical shift of olefinic proton at $\delta_{\mathrm{H}} 7.20(\mathrm{~s}, \mathrm{H}-17)$, while that of the cis compounds at $\delta_{\mathrm{H}} 7.89(\mathrm{~s}, \mathrm{H}-17)[26,36]$.
The molecular formula of $\mathbf{2}$ was assigned as $\mathrm{C}_{21} \mathrm{H}_{24} \mathrm{~N}_{2} \mathrm{O}_{4}$ on the basis of its HRESIMS ion at $\mathrm{m} / \mathrm{z}$ $369.1806[\mathrm{M}+\mathrm{H}]^{+}$(calcd for $\mathrm{C}_{21} \mathrm{H}_{25} \mathrm{~N}_{2} \mathrm{O}_{4}, 369.1809$ ), 16 mass units more than 1 . Comparison the ${ }^{1} \mathrm{H}$ and ${ }^{13} \mathrm{C}$ NMR spectroscopic data of $\mathbf{1}$ with those of $\mathbf{2}$ (Table 2) showed both the compounds contain similar structural features except the downfield shifts of C-3 $\left(\delta_{\mathrm{C}} 75.0,+17.3 \mathrm{ppm}\right)$, C-5 $\left(\delta_{\mathrm{C}} 63.2,+12.1 \mathrm{ppm}\right)$, and C-21 $\left(\delta_{\mathrm{C}} 78.7,+17.6 \mathrm{ppm}\right)$ in 2, which suggested $\mathbf{2}$ was an $N_{4}$-oxide derivative of $\mathbf{1}$ [26]. Moreover, compound 2 shared the same configurations with 1 from their same ECD spectral curves (Fig. 3) and positive signs of their optical rotation, which also supported by detailed NOE correlations (Fig. 2) in the ROESY spectrum of 2.

$3 \beta$-sitsirikine $N_{4}$-oxide (3) was established a molecular formula $\mathrm{C}_{21} \mathrm{H}_{26} \mathrm{~N}_{2} \mathrm{O}_{4}$ on the basis of HRESIMS ion at $\mathrm{m} / \mathrm{z}$ $371.1960[\mathrm{M}+\mathrm{H}]^{+}$(calcd for $\mathrm{C}_{21} \mathrm{H}_{27} \mathrm{~N}_{2} \mathrm{O}_{4}, 371.1965$ ) and the comprehensive analysis of ${ }^{13} \mathrm{C}$ NMR data (Table 2), indicating 10 degrees of unsaturation. Its ${ }^{1} \mathrm{H}$ NMR and ${ }^{13}$ CNMR spectroscopic data (Table 2) were similar to sitsirikine (5) [20]. The visible differences were the downfield shifts of C-3 $\left(\delta_{\mathrm{C}} 71.6,+10.2 \mathrm{ppm}\right), \mathrm{C}-5\left(\delta_{\mathrm{C}} 69.4\right.$, $+7.2 \mathrm{ppm})$, and $\mathrm{C}-21\left(\delta_{\mathrm{C}} 63.0,+9.0 \mathrm{ppm}\right)$ in $\mathbf{3}$ as well as 16 mass units more than $\mathbf{5}$, which suggested that $\mathbf{3}$ was an $\mathrm{N}_{4}$-oxide derivative of sitsirikine (5) [20,26]. Contrary to $\mathbf{1}$ and 2, a negative Cotton effect at $262 \mathrm{~nm}$ revealed the $R$ configuration of C-3 (Fig. 3) [35]. In its ROESY spectrum, NOE correlations of $\mathrm{H}-3$ with both C-14 parahydrogens further supported that the H-3 is in a procumbent equatorial bond ( $\beta$-orientation) (Fig. 2) [29]. Besides, the NOE correlation of $\delta_{\mathrm{H}} 1.47(\mathrm{H}-15)$ with $\delta_{\mathrm{H}} 5.31(\mathrm{H}-19)$ indicated $\mathrm{H}-15$ and $\mathrm{H}-19$ at the same side ( $\alpha$-orientation) while the $\mathrm{H}-20$ at another side, owing to the $\alpha$-orientation of $\mathrm{H}-15$ from its biosynthetic consideration [2]. The $\mathrm{C}-16 R$ of natural sitsirikine (5) have been established on the basis of coupling constants data and chemical methods $[20,37]$. The $\mathrm{H}-17 \mathrm{a}$ and $\mathrm{H}-17 \mathrm{~b}$ appeared as doublet of doublets at $\delta_{\mathrm{H}} 3.97(J=11.0,8.0 \mathrm{~Hz})$ and $3.76(J=11.0$, $6.5 \mathrm{~Hz})$ in sitsirikine (5) while, respectively, at $\delta_{\mathrm{H}} 3.92$ $(J=11.0,8.0 \mathrm{~Hz})$ and $3.71(J=11.0,3.5 \mathrm{~Hz})$ in 16-episitsirikine [20]. The configuration of $\mathrm{C}-16$ in 3 was also kept $R$ from the coupling constants of $\mathrm{H}-17 \mathrm{a}\left[\delta_{\mathrm{H}} 3.92(\mathrm{dd}\right.$, $11.0,8.4 \mathrm{~Hz})]$ and $\mathrm{H}-17 \mathrm{~b}\left[\delta_{\mathrm{H}} 3.52(\mathrm{dd}, 11.0,6.3 \mathrm{~Hz})\right]$ were similar to those of sitsirikine (5).

By structural analysis, we found only compounds $\mathbf{1}$ and 2 showed cytotoxicity in NSCs proliferation assay, while none of the other isolated tetracyclic yohimbine-type alkaloids (3-5, 16-17, and 20-26) (Fig. 1) was active at 10 $\mu \mathrm{M}$, which suggested that the carboxylic acid moieties in $\mathbf{1}$ and $\mathbf{2}$ may be the key groups contributing to NSCs toxicity. Besides, the visible activities difference between $\mathbf{1}$ and $\mathbf{2}$ (Table 1) indicated that the oxidation of $\mathrm{N}_{4}$ may reduce the inhibitory effects of $\mathbf{2}$,which also can be used to explain 
why compounds 6-7 exhibited inhibitory activities but their $N_{4}$-oxide derivative (11-12) did not work. Interestingly, may due to the configuration change of C-7, compound 14 was not active, while its $N_{4}$-oxide derivative (10) inhibited NSCs proliferation at tested concentration.

\section{Experimental Section}

\subsection{Plant Material}

The hook-bearing branches of $U$. rhynchophylla were purchased from the Luo-Si-Wan Chinese herbal medicine market, Kunming, Yunnan province, China, in April 2016, and identified by Dr. Zhang Jun, Kunming Plant Classification Biotechnology Co., Ltd. A voucher specimen (No. WEI_20160418) was deposited in the State Key Laboratory of Phytochemistry and Plant Resources in West China, Kunming Institute of Botany, Chinese Academy of Sciences.

\subsection{General Experimental Procedures}

Optical rotations were performed on a JASCO P-1020 polarimeter. IR spectra were measured on a Bruker FT-IR Tensor 27 spectrometer with $\mathrm{KBr}$ pellets. UV spectra were obtained on Shimadzu UV-2401A spectrometer. 1D-NMR and 2D-NMR spectra were recorded on an AV-600 MHz or a Bruker DRX-400 MHz spectrometer. Coupling constants were expressed in $\mathrm{Hz}$ and chemical shifts were given on a ppm scale with tetramethylsilane as internal standard. HRESIMS were recorded on an API QSTAR Pulsar 1 spectrometer. CD spectra were obtained on a JASCO 810 spectrometer. Column chromatography (CC) was performed on silica gel (200-300 mesh, Qingdao Marine Chemical Ltd., Qingdao, People's Republic of China), Sephadex LH-20 (Pharmacia Fine Chemical Co., Ltd., Sweden), and MCI-gel CHP 20P (75-100 $\mu \mathrm{m}$, Mitsubishi Chemical Co., Ltd). Thin-layer chromatography (TLC) was carried out on silica gel H-precoated plates (Qingdao Haiyang Chemical Co., Ltd.) with $\mathrm{CHCl}_{3} / \mathrm{MeOH}$ (9:1, 4:1, v/v) as developing solvents and spots were visualized by Dragendorff's reagent. High performance liquid chromatography (HPLC) was performed using waters 600 equipment with semi-preparative and preparative $\mathrm{C}_{18}$ columns $(150 \times 9.4$ and $250 \times 21.2 \mathrm{~mm}$, respectively $)$.

\subsection{Extraction and Isolation}

The air-dried and powdered hook-bearing branches of $U$. rhynchophylla $(10 \mathrm{~kg})$ were extracted with $\mathrm{MeOH}$ $(50 \mathrm{~L} \times 3)$ under reflux conditions at $70^{\circ} \mathrm{C}, 3 \mathrm{~h}$ for each time. After removal of the organic solvent under reduced pressure, the residue was dissolved in $0.3 \%$ aqueous hydrochloric acid (v/v); the solution was subsequently basified to $\mathrm{pH}$ 9-10 using ammonia and then extracted with EtOAc $(3 \mathrm{~L} \times 4)$ to give an alkaloidal extract. The extract (52 g) was subjected to a silica gel column $\left(\mathrm{CHCl}_{3} / \mathrm{MeOH}\right.$, 1:0-0:1) to afford fractions (A-F). Fr. A (4.8 g) was subjected to silica gel column chromatography (CC) using a petroleum ether/acetone gradient (10:1-1:9) to afford subfractions (Fr. 1-4). Fr. 3 (1.2 g) was further purified on Sephadex LH-20 using $\mathrm{MeOH}$ under isocratic conditions to afford isocorynoxeine (6) (12 mg), augustine (29) (12 mg), and corynoxeine (13) (8 mg). Fr. 4 (1.5 g) purified on Sephadex LH-20 column by isocratic elution with $\mathrm{MeOH}$ to get a mixture (400 mg), which was then further separated on a semi-preparative $\mathrm{C}_{18}$ HPLC column with a gradient of $\mathrm{MeOH} / \mathrm{H}_{2} \mathrm{O}$ (1:1-1:0) to obtain isorhynchophylline (7) (5 mg) and rhynchophylline (14) (6 mg). Fr. B (9.8 g) was chromatographed on silica gel column $\left(\mathrm{CHCl}_{3} / \mathrm{MeOH}\right.$, 9:1-0:1) to yield seven fractions (Fr. 5-11). Fr. 6 (0.8 g) was purified on Sephadex LH-20 column with $\mathrm{MeOH}$ under isocratic elution and further purified on a semi-preparative $\mathrm{C}_{18} \mathrm{HPLC}$ column $\left(\mathrm{MeOH} / \mathrm{H}_{2} \mathrm{O}\right.$, $1: 1-1: 0, \mathrm{v} / \mathrm{v})$ to afford corynantheine $(\mathbf{2 0})(12 \mathrm{mg})$, dihydrocorynantheine (21) (6 mg), sitsirikine (5) (11 mg), and geissoschizine methyl ether (4) (5 mg). Fr. C (10 g) was fractionated on MCI-gel CHP 20P column by eluting with a gradient of $\mathrm{MeOH}(30-100 \%)$ in $\mathrm{H}_{2} \mathrm{O}$ to yield four fractions (Fr. 12-15). Fr. $14(200 \mathrm{mg})$ was subjected to Sephadex LH-20 CC using $\mathrm{MeOH}$ under isocratic elution and was further purified on a semi-preparative $\mathrm{C}_{18}$ HPLC column $\left(\mathrm{MeOH} / \mathrm{H}_{2} \mathrm{O}, 40: 60-80: 20\right.$, v/v) to yield akuammigine (18) (3 mg), 3-epi-geissoschizine methyl ether (17) (1.2 $\mathrm{mg})$, hirsuteine (22) (7 $\mathrm{mg})$, and nitrocadambine B (28) (9 mg). Fr. D (12 g) was subjected to silica gel CC using a $\mathrm{CHCl}_{3} / \mathrm{MeOH}$ gradient $(9: 1-0: 1)$ to give six fractions (Fr. 16-21). Fr. 20 (800 mg) was subjected to MCIgel CHP 20P column using $\mathrm{MeOH} / \mathrm{H}_{2} \mathrm{O}$ gradient (3:7-1:0) and further separated on Sephadex LH-20 column using $\mathrm{MeOH}$ with isocratic elution to yield (4S)-akuammigine $N$ oxide (8) (2 mg) and hirsuteine $N$-oxide (26) (3 mg). Fr. 21 $(2.5 \mathrm{~g})$ was subjected to Sephadex LH-20 column using $\mathrm{MeOH}$ with isocratic elutionand was further purified on a semi-preparative $\mathrm{C}_{18}$ HPLC column $\left(\mathrm{MeOH} / \mathrm{H}_{2} \mathrm{O}\right.$, 40:60-80:20, v/v) to obtain 3 $\alpha$-dihydrocadambine (27) (8 mg), (4S)-rhynchophylline $N$-oxide (10) (7 mg), and (4S)-corynoxeine $N$-oxide (15) (6 mg). Fr. E (7 g) was chromatographed over silica gel column using a $\mathrm{CHCl}_{3} /$ $\mathrm{MeOH}$ gradient $(4: 1-0: 1)$ to obtain seven fractions (Fr. 22-28). Fr. 24 (200 mg) was further subjected to Sephadex LH-20 column using MeOH to yield geissoschizine methyl ether $N_{4}$-oxide (16) $(10 \mathrm{mg})$ and hirsutine $N$-oxide (23) (9 mg). Fr. 25 (400 mg) was further purified on MCI-gel CHP 20P column with $\mathrm{MeOH} / \mathrm{H}_{2} \mathrm{O}$ gradient $(1: 4-1: 0)$ to 
afford (4R)-akuammigine $N$-oxide (19) $(17 \mathrm{mg}$ ) and hirsutine (24) (13 mg). Fr. 26 (400 mg) was subjected to MCI-gel CHP 20P column using $\mathrm{MeOH} / \mathrm{H}_{2} \mathrm{O}$ gradient (1:4-1:0) and was further purified on a semi-preparative $\mathrm{C}_{18}$ HPLC column (MeOH/ $\mathrm{H}_{2} \mathrm{O}, 40: 60-80: 20$, v/v) to yield dihydrocorynantheine $N$-oxide $(25)(18 \mathrm{mg})$ and $3 \beta$-sitsirikine $N_{4}$-oxide (3) (7 mg). Fr. 27 (300 mg) was repeatedly chromatographed over Sephadex LH-20 column with $\mathrm{MeOH}$ to afford isorhynchophylline $N_{4}$-oxide (11) $(5 \mathrm{mg}$ ), (4S)-isocorynoxeine $\mathrm{N}$-oxide (12) (4 mg), and cadambine (9) $(10 \mathrm{mg})$. Fr. 28 (300 mg) was subjected to MCI-gel CHP 20P column using $\mathrm{MeOH} / \mathrm{H}_{2} \mathrm{O}$ gradient (1:4-1:0) and was further purified on a semi-preparative $\mathrm{C}_{18}$ HPLC column $\left(\mathrm{MeOH} / \mathrm{H}_{2} \mathrm{O}, 30: 70-80: 20, \mathrm{v} / \mathrm{v}\right)$ to yield geissoschizic acid (1) (20 mg) and geissoschizic acid $N_{4}$-oxide (2) (2 mg).

Geissoschizic acid (1): colorless amorphous solid; $[\alpha]_{\mathrm{D}}^{26}$ +31.9 ( $c$ 0.09, MeOH); UV (MeOH) $\lambda_{\max }(\log \varepsilon): 269$ (4.05), 223 (4.74), 207 (4.60) nm; ECD (c $0.15 \mathrm{mM}$, $\mathrm{MeOH}) \lambda(\Delta \varepsilon): 218(-7.19), 234(+3.71), 267(+2.48)$; IR $(\mathrm{KBr}) v_{\max } 3421,2933,1644,1382,1238$, and $1132 \mathrm{~cm}^{-1}$; HRESIMS $m / z \quad 353.1852 \quad[\mathrm{M}+\mathrm{H}]^{+} \quad$ (calcd for $\mathrm{C}_{21} \mathrm{H}_{25} \mathrm{~N}_{2} \mathrm{O}_{3}$, 353.1860); ${ }^{1} \mathrm{H}$ and ${ }^{13} \mathrm{C}$ NMR data, see Table 2.

Geissoschizic acid $N_{4}$-oxide (2): colorless amorphous solid; $[\alpha]_{\mathrm{D}}^{21}+101.8(c 0.11, \mathrm{MeOH}) ; \mathrm{UV}(\mathrm{MeOH}) \lambda_{\max }(\log$ c): 269 (3.42), 223 (4.11), 208 (4.00) nm; ECD (c $0.61 \mathrm{mM}, \mathrm{MeOH}) \lambda(\Delta \varepsilon): 219(-8.02), 231(+4.21)$, 266 (+2.03); IR (KBr) $v_{\max } 3393,2943,1636,1448,1246$, and $1113 \mathrm{~cm}^{-1}$; HRESIMS $\mathrm{m} / z, 369.1806[\mathrm{M}+\mathrm{H}]^{+}$(calcd for $\left.\mathrm{C}_{21} \mathrm{H}_{25} \mathrm{~N}_{2} \mathrm{O}_{4}, 369.1809\right) ;{ }^{1} \mathrm{H}$ and ${ }^{13} \mathrm{C} \mathrm{NMR}$ data, see Table 2 .

$3 \beta$-sitsirikine $N_{4}$-oxide (3): colorless amorphous solid; $[\alpha]_{\mathrm{D}}^{24}+104.3(c 0.04, \mathrm{MeOH}) ; \mathrm{UV}(\mathrm{MeOH}) \lambda_{\max }(\log \varepsilon)$ : 273 (4.04), 221 (4.72) nm; ECD (c $0.13 \mathrm{mM}, \mathrm{MeOH}) \lambda$ $(\Delta \varepsilon): 213(+7.41), 234(+1.88), 262(-2.07)$; IR $(\mathrm{KBr})$ $v_{\max } 3414,2930,1727,1633,1454,1319$, and $1063 \mathrm{~cm}^{-1}$; HRESIMS $m / z 371.1960[\mathrm{M}+\mathrm{H}]^{+}$(calcd for $\mathrm{C}_{21} \mathrm{H}_{27} \mathrm{~N}_{2} \mathrm{O}_{4}$, 371.1965); ${ }^{1} \mathrm{H}$ and ${ }^{13} \mathrm{C}$ NMR data, see Table 2 .

\subsection{NSCs Proliferation Assay}

Neural stem cells (NSCs) were grown in serum-free growth medium (DMEM/F12 1:1; Hyclone) containing $20 \mathrm{ng} / \mathrm{mL}$ human epidermal growth factor (EGF, Gibco), $20 \mathrm{ng} / \mathrm{mL}$ human fibroblast growth factor (bFGF, Gibco), $1 \%$ penicillin/streptavidin, $1 \% \mathrm{~N}_{2}$ supplement (Gibco), $1 \times \mathrm{B} 27$ (Gibco) and $10 \mu \mathrm{g} / \mathrm{mL}$ heparin as previously described [38-39]. The media were allowed to change every 2 days. The resulting neurospheres were passaged every 3-4 days to single-cell suspension for continued growth and expansion of stem cells. For treatment experiments, NSCs were treated with $0.1 \%$ DMSO, indicated compounds $(10 \mu \mathrm{M})$, and puromycin (positive control) $(10 \mu \mathrm{M})$.

Cell clusters generated by adult neural stem cells (NSCs) proliferation were trypsinized into single cell and evenly plated into 96 well plate overnight. NSCs proliferation rate was measured by SRB assay according to the standard protocol [40]. Briefly, cells were exposed to DMSO and the test compounds and incubated at $37{ }^{\circ} \mathrm{C}$ in a humidified incubator with $5 \% \quad \mathrm{CO}_{2}$ for $48 \mathrm{~h}$, without removing the cell culture supernatant, cells were fixed with $16 \%$ TCA and incubated at $4{ }^{\circ} \mathrm{C}$ for $1 \mathrm{~h}$. Plates were washed 5 times with water and air dried. A $100 \mu \mathrm{L}$ of sulforhodamine B solution $0.4 \%(\mathrm{w} / \mathrm{v})$ in $1 \%$ acetic acid was added into each well. After $10 \mathrm{~min}$ at room temperature, the plates were rinsed five times with $1 \%$ acetic acid quickly to remove unbound dye and then air dried. Then $50 \mu \mathrm{L} 10 \mathrm{mM}$ un-buffered Tris-base was added to solubilize the protein-bound dye. The absorbance was read on automated plate reader (Epoch, Biotek) at $515 \mathrm{~nm}$. Each compound was treated in 3 independent wells per experiment, and the assay was repeated at least 3 times. The value of DMSO was set to 1 , and the other values were normalized to DMSO.

Acknowledgements The authors are grateful to the National Natural Science Foundation of China $(81225024,31500292,31770388)$ for financial support.

\section{Compliance with Ethical Standards}

Conflict of interest The authors declare no conflict of interest.

Open Access This article is distributed under the terms of the Creative Commons Attribution 4.0 International License (http:// creativecommons.org/licenses/by/4.0/), which permits unrestricted use, distribution, and reproduction in any medium, provided you give appropriate credit to the original author(s) and the source, provide a link to the Creative Commons license, and indicate if changes were made.

\section{References}

1. J.S. Shi, J.X. Yu, X.P. Chen, R.X. Xu, Acta. Pharmacol. Sin. 24, 97-105 (2003)

2. A. Ndagijimana, X. Wang, G. Pan, F. Zhang, H. Feng, O. Olaleye, Fitoterapia 86, 35-47 (2013)

3. J. Lee, D. Son, P. Lee, S.Y. Kim, H. Kim, C.J. Kim, E. Lim, Neurosci. Lett. 348, 51-55 (2003)

4. W. Liu, Z.Q. Zhang, X.M. Zhao, Y.S. Gao, China J. Chin. Mater. Med. 31, 763-765 (2006)

5. Y. Shimada, H. Goto, T. Itoh, I. Sakakibara, M. Kubo, H. Sasaki, K. Terasawa, J. Pharm. Pharmacol. 51, 715-722 (1999)

6. T.H. Kang, Y. Murakami, H. Takayama, M. Kitajima, N. Aimi, H. Watanabe, K. Matsumoto, Life Sci. 76, 331-343 (2004)

7. Y.F. Xian, Z.X. Lin, Q.Q. Mao, S.P. Ip, Z.R. Su, X.P. Lai, Cell. Mol. Neurobiol. 32, 353-360 (2012) 
8. T.H. Kang, Y. Murakami, K. Matsumoto, H. Takayama, M. Kitajima, N. Aimi, H. Watanabe, Eur. J. Pharmacol. 455, 27-34 (2002)

9. N. Egashira, K. Hayakawa, M. Osajima, K. Mishima, K. Iwasaki, R. Oishi, M. Fujiwara, J. Pharmacol. Sci. 105, 211-214 (2007)

10. K. Matsumoto, R. Morishige, Y. Murakami, M. Tohda, H. Takayama, I. Sakakibara, H. Watanabe, Eur. J. Pharmacol. 517, 191-199 (2005)

11. J.Y. Zhou, S.W. Zhou, Fitoterapia 83, 617-626 (2012)

12. C. Zhao, W. Deng, F.H. Gage, Cell 132, 645-660 (2008)

13. F.H. Gage, Science 287, 1433-1438 (2000)

14. C.R. Freed, P.E. Greene, R.E. Breeze, W.Y. Tsai, W. DuMouchel, R. Kao, S. Dillon, H. Winfield, S. Culver, J.Q. Trojanowski, D. Eidelberg, S. Fahn, N. Eng, J. Med. 12, 710-719 (2001)

15. D.J. Chang, M.Y. Jeong, J. Song, C.Y. Jin, Y.G. Suh, H.J. Kim, K.H. Min, Bioorg. Med. Chem. Lett. 21, 7050-7053 (2011)

16. X.W. Yang, C.P. Yang, L.P. Jiang, X.J. Qin, Y.P. Liu, Q.S. Shen, Y.B. Chen, X.D. Luo, Org. Lett. 16, 5808-5811 (2014)

17. S.K. Tiwari, S. Agarwal, B. Seth, A. Yadav, R.S. Ray, V.N. Mishra, R.K. Chaturvedi, Mol. Neurobiol. 52, 1735-1757 (2015)

18. X. Wei, A. Khan, D. Song, Z. Dai, Y.P. Liu, H.F. Yu, B. Wang, P.F. Zhu, C.F. Ding, X.D. Zhao, Y.F. Wang, X.D. Luo, Nat. Prod. Bioprospect. 7(4), 323 (2017)

19. I. Sakakibara, S. Terabayashi, M. Kubo, M. Higuchi, Y. Komatsu, M. Okada, K. Taki, J. Kamei, Phytomedicine 6, 163-168 (1999)

20. R.T. Brown, J. Leonard, Tetrahedron Lett. 20, 1805-1808 (1979)

21. J.N. Zheng, D.Y. Wang, Guiding J. Tradit. Chin. Med. Pharm. 15, 80 (2009)

22. L. Merlini, G. Nasini, J.D. Phillipson, Tetrahedron 28, 5971-5975 (1972)

23. W.B. Xin, G.X. Chou, Z.T. Wang, Chin. Tradit. Herbal Drugs 40, 204-207 (2009)
24. B. Ma, C.F. Wu, J.Y. Yang, R. Wang, Y. Kano, D. Yuan, Three new alkaloids from the leaves of Uncaria rhynchophylla. Helv. Chim. Acta. 92, 1575-1585 (2009)

25. E.J. Shellard, J.D. Phillipson, K. Sarpong, Xenobiotica 1, 455-456 (1971)

26. W. Qi, S.J. Yue, J.H. Sun, J.W. Simpkins, L. Zhang, D. Yuan, J. Asian Nat. Prod. Res. 16, 876-883 (2014)

27. N. Aimi, E. Yamanaka, N. Shinma, M. Fujiu, J. Kurita, S. Sakai, J. Haginiwa, Chem. Phram. Bull. 25, 2067-2071 (1977)

28. E. Wenkert, J.S. Bindra, C.J. Chang, D.W. Cochran, F.M. Schell, Accounts Chem. Res. 7, 46-51 (1974)

29. H.Q. Pan, W.Z. Yang, Y.B. Zhang, M. Yang, R.H. Feng, W.Y. Wu, D.A. Guo, Anal. Bioanal. Chem. 407, 6057-6070 (2015)

30. N. Aimi, E. Yamanaka, M. Ogawa, T. Kohmoto, K.I. Mogi, S.I. Sakai, Heterocycles 10, 73-78 (1978)

31. X.Y. Xu, S.Z. Li, Q.S. Song, Nat. Prod. Res. Dev. 23, 393-398 (2011)

32. L.L. Liu, S.F. Li, Q. Zhang, F. Zhu, W. Yang, H.P. He, X.J. Hao, Chinese J. Chem. 31, 79-83 (2013)

33. T.Y. Au, H.T. Cheung, J. Chem. Soc., Perkin Trans. 1, 13 (1973)

34. W.W. Jiang, J. Su, X.D. Wu, J. He, L.Y. Peng, Q.S. Zhao, Nat. Prod. Res. 29, 842-847 (2015)

35. R.T. Brown, W.P. Blackstock, Tetrahedron Lett. 13, 3063-3065 (1972)

36. L. Li, P. Aibibula, Q.L. Jia, Y.X. Jia, Org. Lett. 19, 2642-2645 (2017)

37. J.P. Kutney, R.T. Brown, Tetrahedron 22, 321-336 (1966)

38. J.A. Gilley, C.P. Yang, S.G. Kernie, Hippocampus 21, 33-47 (2011)

39. C.P. Yang, J.A. Gilley, G. Zhang, S.G. Kernie, Development 138, 4351-4362 (2011)

40. V. Vichai, K. Kirtikara, Nat. Protoc. 1, 1112-1116 (2006) 